\title{
Overview of the treatment of historical industrial heritage in engineering graphics
}

\author{
José Ignacio Rojas-Sola* and Miguel Castro-Garcia \\ Department of Engineering Graphics, Design and Projects, University of Jaen, Spain. \\ Accepted 22 November, 2011
}

\begin{abstract}
This article presents a comprehensive review of the stages of research when addressing the issue of historical industrial heritage from the point view of engineering graphics, looking at its influence on all stages of the value chain. It provides a contextual introduction, explaining the research, the aim pursued and the priority objectives of this type of work. It also presents the methodology and the materials used, specifying important details needed to obtain a realistic result, such as fieldwork, 3D virtual modeling, virtual reconstruction, and more usual techniques used such as augmented reality and virtual reality. Finally, the dissemination of the results and the advantages and disadvantages of the virtual reconstructions are presented.
\end{abstract}

Key words: Historical industrial heritage, computer-aided design, computer animation, engineering graphics, computer graphics, virtual heritage, industrial archaeology.

\section{INTRODUCTION}

If a web search is carried out in a search engine such as Google of the term 'heritage', there are 424.000,000 results (search made on $20^{\text {th }}$ August, 2011). This shows the growing importance of heritage in any of its facets.

The importance of heritage is also shown by the existence of many prestigious international congresses, such as World Heritage in the Digital Age, organized by the UNESCO World Heritage Centre, or International Symposium on Virtual Reality, Archaeology and Cultural Heritage, as well as the many high-impact journals (such as Journal of Cultural Heritage), websites (http://www.virtualheritage.net,

http://www.itabc.cnr.it/VHLab) or the European Commission's programmes on Cultural Heritage and Technology Enhanced Learning (http://cordis.europa.eu/fp7/ict/telearndigicult/home_en.html).

The UNESCO World Heritage Centre (http://whc.unesco.org/en/35/) defines heritage as our legacy from the past, which we live with and which we pass on to future generations. In 2010, the University of Jaén received a special mention in the quality of

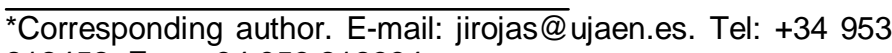
212452. Fax: +34 953212334 . international excellence campus in natural and cultural heritage, awarded by the Spanish Ministry of Science and Innovation in the framework of the International Excellence Programme (CEI). This recognition relating to cultural heritage means that research carried out at the University of Jaen into heritage in any of its aspects is highly valued, whether it deals with material heritage (historical, artistic, archaeological, architectural, industrial, bibliographical or documental) or immaterial or intangible heritage (folklore, oral traditions or know-how).

Our knowledge area is engineering, and given that any branch of scientific knowledge has to include as a discipline its own evolution, this has led to the research of historical industrial heritage through the study of both plans and projects in archives and libraries, and also of material remains.

In addition, this research line contributes to revaluing a legacy related to engineering, which is very often undervalued. A clear example can be seen in the industrial buildings of Johannesburg, which are of great value within industrial heritage, and which are often abandoned and in time demolished (Laeuferts and Mavunganidze, 2009). Its immediate results are projects whose objective is the restoration of this heritage for new ends, and approaches, which aim to preserve this heritage.

Historical industrial heritage is today being approached 
from both technical and historical perspective. For example, in Spain, Law 14/2007 of $26^{\text {th }}$ November on historical heritage in Andalucia, in section VII articles 65 to 68 , recognizes -for the first time- the protection of this type of heritage, which was already reflected in the National Plan of industrial heritage from 2000, based on Law $16 / 1985$ of $25^{\text {th }}$ June on Spanish Historical Heritage. Within this plan, there are 49 undertakings in Spain, dealing with industrial heritage and landscape, protecting mining areas, mills, factories and quarries, among other examples.

\section{INDUSTRIAL HERITAGE}

There are a lot of initiatives for the recovery of our heritage, both general and industrial, but owing to the lack of a defined methodology these projects do not produce the desired result, as recovery should follow a specific methodology according to the type of heritage.

Many organizations work on the study, analysis and recovery of industrial heritage, some linked to industrial archaeology, such as TICCIH (The International Committee for the Conservation of Industrial Heritage, http://www.mnactec.cat/ticcih/), AIA (Association for Industrial Archaeology, http://www.industrialarchaeology.org.uk/), or to the history of technology, such as SHOT (Society for the History Of Technology, http://www.historyoftechnology.org), as well as, the branches of UNESCO which are devoted to the study of the many types of heritage: architectural, industrial, cultural or ethnographic, among others.

There are currently many examples of industrial heritage sites which are threatened by disappearance, and are in many cases in a state of ruin. In addition, in many cases the efforts of archaeologists, conservationists and restorers are not enough. In our personal view, heritage related to abandoned buildings, either architectural or industrial, is often lost owing to urban planning interests or the lack of conservation projects, which would give new life to the area and new opportunities for the people who live there. In the case of historical industrial heritage, which has been used in production processes, the situation is even clearer, not only because of its increased scope in comparison with industrial architecture, but also because disused machinery suffers greater deterioration in terms of operation.

Therefore, each time a part of this heritage is lost, the chance to study, analyze and evaluate its impact on society is also lost. However, there are initiatives in place for the recovery of industrial heritage; a clear example can be seen in Science and Technology museums, which are becoming increasingly common, as they are a way of safeguarding a culture linked to the socio-economic development of a given geographical area in a country (Rojas-Sola, 2006). This example is much clearer in the case of facilities and equipment linked to preindustrialization (windmills, watermills, fulling mills or oil presses, among others), as they date from before the industrial age and their age makes them more susceptible to deterioration and destruction.

In general, historical industrial heritage consists of buildings that house productive activity as efficiently as possible, relegating possible aesthetic factors which would offer greater visual beauty. However, the importance of this type of heritage lies in the industrial procedures and techniques, which were housed in these buildings. From an engineering perspective, the recovery of productive machinery, procedures and techniques can aid in the further development of these techniques, as well as forming the legacy which different civilizations have contributed to development. There are many examples, such as olive presses or flour mills (either windmills or watermills), which represented an important core of the economy and social and industrial development of societies. Therefore, their recovery and study are very important, especially for industrial history.

In addition, the recovery of monuments and other buildings of cultural interest has a considerable socioeconomic repercussion. Historical knowledge is enhanced, along with knowledge of techniques and customs, which may have been lost with time, and furthermore, economic development is promoted, especially in the tourism sector, by increased numbers of visitors to different monuments and historical buildings.

Historical industrial heritage also has a close relationship with industrial archaeology. Much has been written about this discipline, with different definitions, for example "...The objective of industrial archaeology is the discovery, analysis, registry and conservation of past industrial remains" (Buchanan, 1972), or "The aim of industrial archaeology is the discovery, cataloguing and study of physical remains from the industrial past, in order to know through them significant aspects of working conditions and technical and productive processes" (Hudson, 1971). This is therefore a cross-discipline area combining others such as history, sociology, ethnography, technology, town planning or geography.

Industrial archaeology registers, researches and analyses material remains of industrial society, with two key concepts: material culture and working memory. In order to study working memory, industrial archaeology draws on spoken and written accounts from people who provide their own recollections. Spoken accounts are extremely important because they are recent accounts from people who worked in industrial settings. The study of material culture consists of analysis including other social sciences such as ethnography, anthropology, sociology and history. It therefore employs different sources: cartography of historical and modern maps; company or local authority archives; iconography and photography; films; industrial catalogues, etc. Therefore, historical industrial heritage is composed of all the 
remains generated by the productive activity of industrial sectors, the use of natural resources, energy production, transformation of agricultural products, and even documental sources such as company archives, questionnaires, films, photographs and maps. Not all of these elements need to be preserved, but they do need to be studied and suitably registered. The criterion for the selection of elements is that they have had a functional role in production.

Therefore, industrial archaeology and the history of technology have in engineering a key element to complete a broad vision of the study of historical industrial heritage, as the majority of these studies are in nature historical, ethnographic tourism (Fuentes et al., 2010), philological or architectural (Med, 2010), but rarely do they contain an engineering perspective.

The recovery of industrial heritage is in many cases linked to the history of technology, as this is a key element in the study of the technological evolution of any machine or device. Hence, engineering graphics, and more specifically infographic techniques, are an essential part of the study of the history of technology, given the universal nature of graphic language. This can be seen in the large number of articles which deal with graphic reconstructions of different elements of machinery or devices (Penestri et al., 2006; Pérez-Martin et al., 2011; Rojas-Sola, 2005; Rojas-Sola and Amezcua-Ogáyar, 2005a; Rojas-Sola and Domene-Garcia, 2005; RojasSola et al., 2006, 2007; Rojas-Sola and López-Garcia, 2007a; Rojas-Sola and Contreras-Anguita, 2010), and therefore also study them from a technical perspective (Rojas-Sola and Amezcua-Ogayar, 2005b).

Infographic techniques are particularly important in the reconstruction of monuments and buildings with special socio-cultural interest. This is partly due to economic factors, as a virtual reconstruction is possible at a fraction of the cost of a conventional reconstruction, although, human behavior must be considered (Popovici et al., 2010). With this in mind, virtual heritage tours can be developed using interactive narrations which allow visitors to experience the surroundings of historical sites (Tuck and Kuksa, 2009).

One of the main consequences of this is the possibility to reconstruct monuments where a conventional reconstruction is not viable, either owing to questions of cost or because they do have the attraction of other monuments. This is the case of part of historical industrial heritage whose cultural richness is in the evolution of techniques and machinery over time.

In terms of virtual heritage, researchers believe that the existence of this heritage encourages people to visit the real site, and that it provides extra knowledge which complements an on-site visit (Refsland et al., 2000); therefore people can take advantage of the changes and opportunities it offers (Arnold, 2001). Working trends in virtual heritage can be divided into three different phases: complete 3D documentation, 3D representation (from historical reconstruction to visualization) and 3D dissemination (from immersive environments to augmented reality) (Addison, 2000). Many applications have been developed which deal with historical sites or buildings, but in 2000 it was predicted that in the decade from 2000 to 2010, progress in this field would be centered on virtual historical industrial heritage (Stone and Ojika, 2000).

The role played by synthesis images in the recovery of historical industrial heritage has grown exponentially in recent years. They allow the conservation and interpretation of a site, building or object in ways previously impossible to imagine, using techniques such as photography. What is more important is that in using virtual models, all the work is carried out without altering the original real model. In general, improvements are constantly being made in the treatment and dissemination of the computer graphics results in the study and analysis of cultural heritage (Rojas-Sola et al., $2011 b)$. Other advantages can be found in the objectives of computer animation. First, there is a socio-cultural objective, as the collective historical memory of a given area is recovered, giving data on the evolution of society; second, there is a clear educational objective which shows details of an abandoned culture and influences positively the teaching and learning process (Rojas-Sola and Lopez-Garcia, 2007b); and third, there is technological interest, as the methodology used in the process of applying computer animation techniques is valuable know-how. The verisimilitude of the image obtained by computer should be questioned in the same way as a figure in a journal, although, it is not common for digital media to do this (Bakker et al., 2003).

\section{Research lines}

The systematic study of remains related to historical industrial heritage permits various effects:

1. The reconstruction of old industrial processes.

2. The definition of past technological situations.

3. A view of construction styles and techniques in industrial buildings and machinery design.

4. Models of shapes and forms which may be animated and their operation shown using animation, which would not be viable in other ways.

5. The study of design codes, operating parameters and possible improvements to and optimization of machinery, which allows us to discover the technological baggage rural areas where this machinery was to be found.

It is still possible today to find this type of facilities, which owing to a number of factors such as postponements or the economic conditions of communities have continued to work until the late $20^{\text {th }}$ century, given that the evolution of technology has not been lineal. It is common for the 
value of this type of facilities to lead to their being declared as cultural heritage, and to the need for restoration; it is here that engineering graphics should play an important part. The geometric documentation of heritage is becoming increasingly important as a key methodological aspect in the conservation, management and dissemination of heritage. This proposal has been laid out in detail in a doctoral thesis (Valle, 2007), which groups its results in three areas: registers of geometric information, graphic representations, and presentations (Valle, 2009).

Among the examples of historical industrial heritage that are most commonly studied are oil presses, flour mills, fulling mills, potters' mills, grape presses, paper mills, powder mills, salt mils rice mills, foundries, electric mills, flour mills, saw mills, explosives factories, ceramics factories, hydraulic, wind or gas energy. This type of research has five main objectives:

1. Cultural applications: The recovery of the historical memory of the final product is obtained from a technological perspective using a virtual reconstruction of the machinery and its architecture.

2. Educational applications: Another no less important objective is to raise the awareness of university students of the need to preserve historical industrial heritage. Many industrial buildings that should have been preserved owing to their cultural value, and in many cases this loss has been the result of ignorance and laziness on the part of promoters and project leaders. This is taught in subjects such as history of technology.

3. Applications for rural tourism: It has become evident that the aesthetic value of industry or the culture of industry (technology, the semantics of words and phrases related to trades which have disappeared, their evolution and history) con contribute to promoting rural tourism and in the design of routes to support this important area of the economy.

4. Museological applications: Various activities can be carried out, such as the rehabilitation and restoration of various examples of historical industrial heritage using computer animations, augmented reality and virtual reality.

5. Facilitate the creation of an international network of historical industrial heritage which cover all historical, graphic, technological, architectural and ethnographic elements.

\section{Priority objectives}

The general objectives of this type of research are:

1. To study and methodize existing bibliographic information about the element of heritage under study.

2. To draw up an inventory and technical description of physical remains and their content.

3. To carry out industrial archaeology studies from all perspectives (historical, architectural, technological, graphic and inventory).

4. To publish all related information online.

As well as this overall context, the specific objectives which should be pursued are:

1. To study the historical evolution and characterization from an architectural perspective of the element of heritage under study.

2. To draw up an inventory using GPS and GIS techniques.

3. To carry out fieldwork with collection of data (photographs, diagrams, sketches of machines and mechanisms, materials and spoken accounts of operating parameters, among others), which is necessary for graphic reconstruction.

4. Engineering graphics work (3D graphic reconstruction and computer animation of operation and its environment, as well as the generation and labeling of plans of functional elements and the development of applications with augmented and virtual reality techniques).

5. Graphic and technical analysis of the level of adaptation of the different machines which play a role in the productive process.

6. Technological analysis of the elements under study and engineering considerations of operating parameters, production calculations and possible optimizations, using classic engineering calculations and checks using computer assisted engineering.

7. Critical considerations of the technological solutions provided in the contemporary cultural environment, and in comparison with other typologies in nearby areas.

\section{MATERIALS AND METHODS}

In order to fulfill the objectives earlier stated, a methodology is followed with the following stages: Fieldwork, 3D virtual modeling, 3D virtual reconstruction, interaction techniques to heritage such as augmented reality and virtual reality, and lastly, the dissemination.

The majority of the computer graphics techniques used in the recovery of industrial heritage is common to those of any other example of cultural heritage. However, there are some factors which make these techniques different, basically owing to the use of engineering techniques in the software. This means that in the virtual reconstruction of industrial plants and machinery, some concepts are used which are not present in other areas of cultural heritage, such as activity flows and operation (Montoro et al., 2009), input and output features, or mechanical performance and productivity (Fuentes et al., 2011), among others.

In addition, the complexity of the machines and devices used is significant. An industry has diverse machinery with a multitude of parts, auxiliary power and refrigeration 


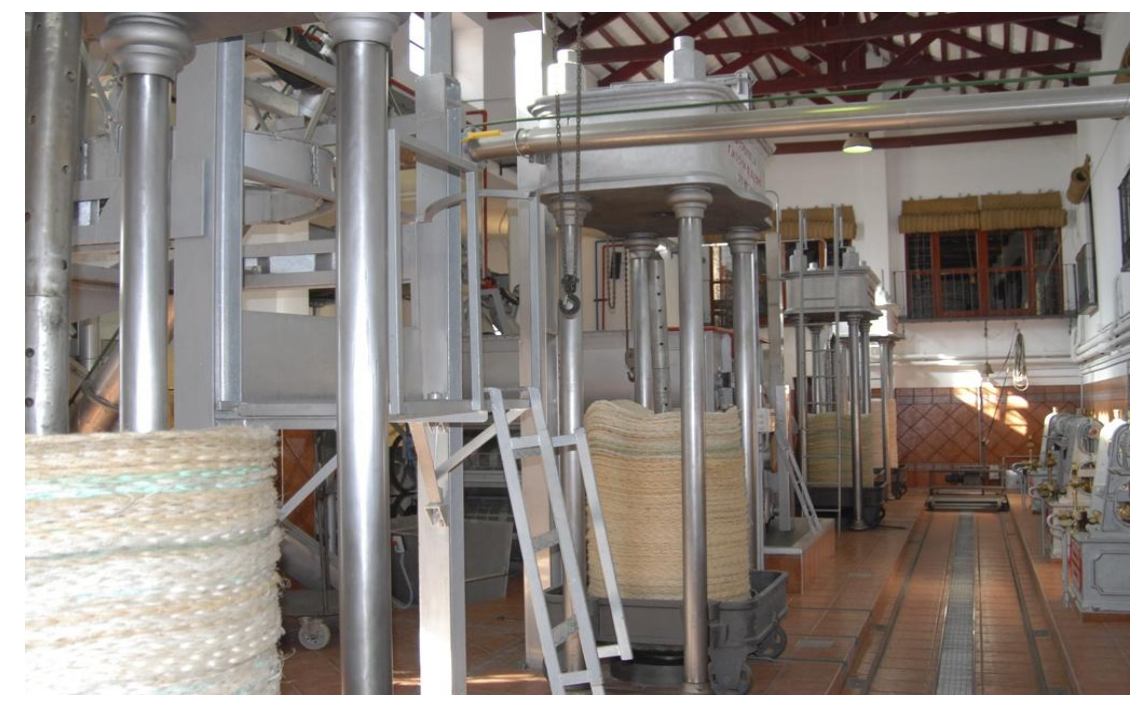

Figure 1. Hydraulic olive oil press.

systems, as well as, spatial flows. However, in the case of historical industrial heritage, the graphical and technical information relating to these systems no longer exists or is not detailed enough to reproduce faithfully the elements under study.

\section{Fieldwork}

Firstly, when working on an overall level with a type of heritage, this stage normally involves an inventory. This inventory stage seeks to locate geographically all the examples of heritage to be studied, as well as making a detailed description of each one from a descriptive and functional point of view, thus, generating data which are stored in a database. A model inventory form has to be designed and then completed, using GPS location and an in-situ inspection. In order to complete this stage, a photographic reportage should be made, along with spoken accounts if possible, and geometric data. This photographic reportage should be made with a high resolution camera, as this resolution will determine the realistic appearance of the final 3D virtual model, as well as other studies based on photogrammetric techniques.

The spoken accounts of any people who worked in the environment are usually extremely helpful, as they shed light on the operation and other details of the productive life of the machinery. Lastly, the collection of data can be carried out in various ways: using empirical techniques such as measurements made with tape measures or laser measuring devices, and also using 3D laser scanning techniques and digital photogrammetry techniques. There are many examples of the use of 3D laser scanning with elements of historical heritage (Bruno et al., 2010; Martin Lerones et al., 2010; Yakar et al., 2009), photogrammetric techniques (Aydin et al., 2010;
Alyilmaz et al., 2010), their application to archaeological documentation (Ergincan et al., 2010), teledetection (McAdams et al., 2010, Alkan and Bulut, 2010) and even of the importance of calibrating stereo-photogrammetric systems (Goktepe, 2010).

\section{D Virtual modeling}

In order to carry out this stage successfully, it is necessary to have completed the fieldwork stage. The 3D virtual modeling is done using CAD techniques; this is one of the most critical stages in the research, as it generates the structure on which the following stages will be based. Therefore, accuracy and detail are fundamental at this stage in order that the final result is as realistic as possible, as well as maintaining the graphic quality established at the beginning of the research. This means that the modeling tools used should be suitable for the characteristics of the desired result.

There is a wide range of software including Autodesk Inventor Professional, SolidWorks, SolidEdge, ProEngineer or CATIA, which, depending on the desired objective, have characteristics which are more or less suitable to be studied using Computer-Aided Engineering techniques. All have common characteristics, such as a functional design, automatic model generation, automatic updates, materials libraries or finite elements analysis. An example is shown below, a hydraulic press used to obtain olive oil (Figure 1) and its $3 d$ model created with autodesk inventor professional 2010 (Figure 2).

The hydraulic press is one of the most recent examples of industrial heritage, and has been used in olive oil factories until the end of the $20^{\text {th }}$ century. It is also one of the presses with the largest production in history. It is 


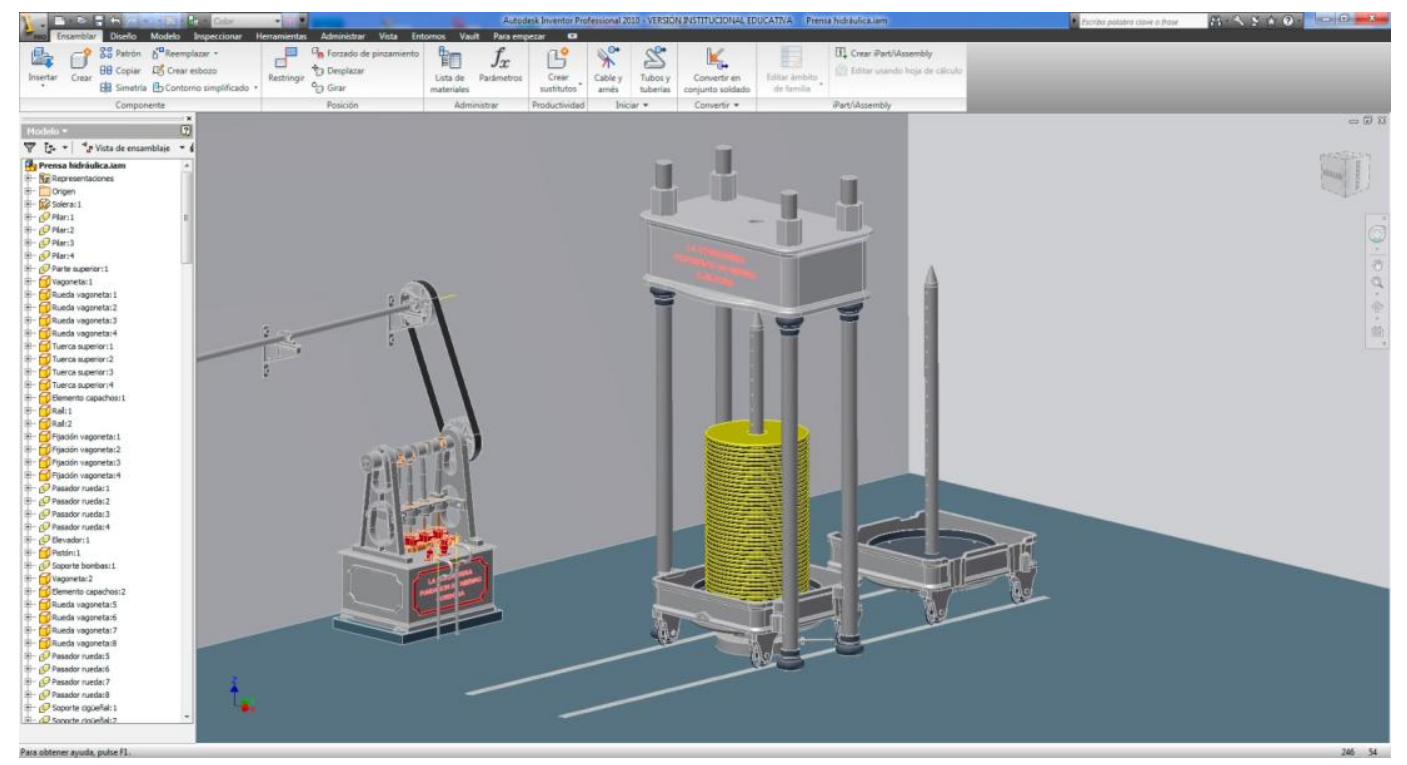

Figure 2. 3D virtual model of the press created with autodesk inventor professional 2010 .

based on the application of Pascal's principle, and was developed by Joseph Bramah in 1796.

It is therefore a noteworthy example of historical industrial heritage which is the object of study in the research project of this paper. In some cases it may be useful to create a 3D printout of the virtual model, which will provide a real scale model showing notable visual characteristics.

\section{D Virtual reconstruction}

Once the virtual model has been obtained, there follows the process or texturing and lighting, and then rendering, which provide the results for the digital post-production stage. All these processes are carried out with graphic creation and computer animation software, such as for example Autodesk 3ds Max, Autodesk Maya or Viz Poser, among others. This is the stage that requires the greatest amount of preparation in order to obtain realistic results. In the example shown, the software used is Autodesk 3ds Max 2010.

\section{Preparation and application of materials}

In this stage repetition textures are created which are to be applied to the different parts of all the objects which are present in the model. The best option is to extract the textures from the original real elements, although the textures of parts of these elements may not be able to be achieved, and in this case it is necessary to use materials libraries. In many occasions, it is also necessary to retouch the image with specific software, for example Adobe Photoshop.

For the creation of repetition texture (Figure 3), mosaics are made. This is a texture generation method (García-Fernández, 2003) which is based on creating a large surface, the edges of which are similar to the opposite edges, so that when the surface is applied the joins between different sections are not noticeable. Once the mosaics have been produced, corrections can be applied using different parameters of the image. Some of the most important are color balance, brightness, saturation, contrast, exposure, channel mixing and filter effects.

\section{Scene lighting}

The lighting of a scene is a very complex task, and it is necessary to find the natural and correct location of the light sources so that the objects in the scene can be viewed well. The factors which play a role in lighting are the sources, the type of lighting used, the shape and texture of the objects and the characteristics of the receiver.

There are various light sources, correlated with the rendering application used (rendering engine). However, they can be classified by type and form of light emission. Among the types of light are standard and photometric. The former include the most simple types which simulation lighting from a point in space which projects light in predetermined directions. The latter are more advanced, and simulate real characteristics of light sources. This involves using global calculation systems, 


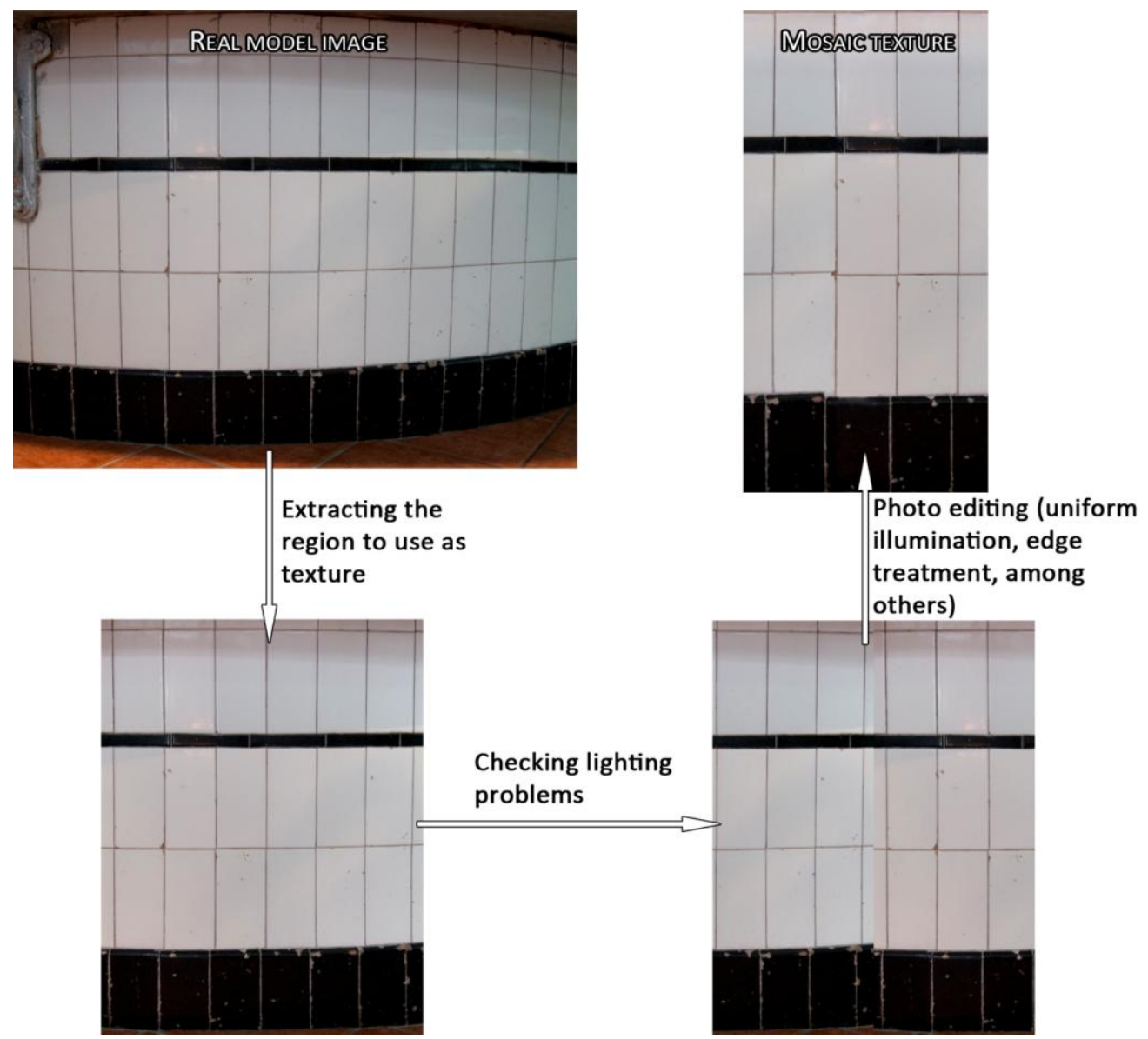

Figure 3. Creation procedure of a repetition texture of a part of a hydraulic press.

which are used in the windmill under study.

There are fundamentally four lighting methods which use their respective algorithms for generating the lighting system, and they determine the quality of rendering and the calculation of light times:

1. Rasterization: This geometrically projects $3 D$ objects onto an image plane without using advanced optical effects

2. Ray casting: This considers that the scene is observed from a defined perspective, and calculates the observed image based solely on geometry and simplified optical laws, in order to calculate the intensity of reflection. It is used in real-time applications.

3. Radiosity: This method attempts to simulate the way in which surfaces which are directly lit by a light source light other nearby surfaces.

4. Ray tracing: This method generates images by tracing the rays of light through pixels on the image plane. It is used above all to create realistic effects.

Computers are available with high performance graphic hardware which can carry out ray tracing in a short time, and with increasingly spectacular results (Figure 4). Another aspect to bear in mind when lighting a scene is the shape and texture of the objects present. Some of the most important parameters are reflections of light beams and the subdivisions which are created on surface elements. These are very important in justifying the empirical nature of the lighting stage, as not all scenes can be treated using the same standard, given that there are many different possible shapes and form which condition the overall behavior of the lighting model. Lastly, lighting depends on the receiver, which in general is a static or dynamic camera which views the scene.

\section{Cameras}

Another of the issues to be dealt with in order to complete the

stages before rendering is the creation of cameras. In general, irrespective of the software used, these tend to emulate real cameras, such as fixed, video or cinema cameras. The majority of the key factors in a camera must be defined, such as focal length, zoom aperture, 


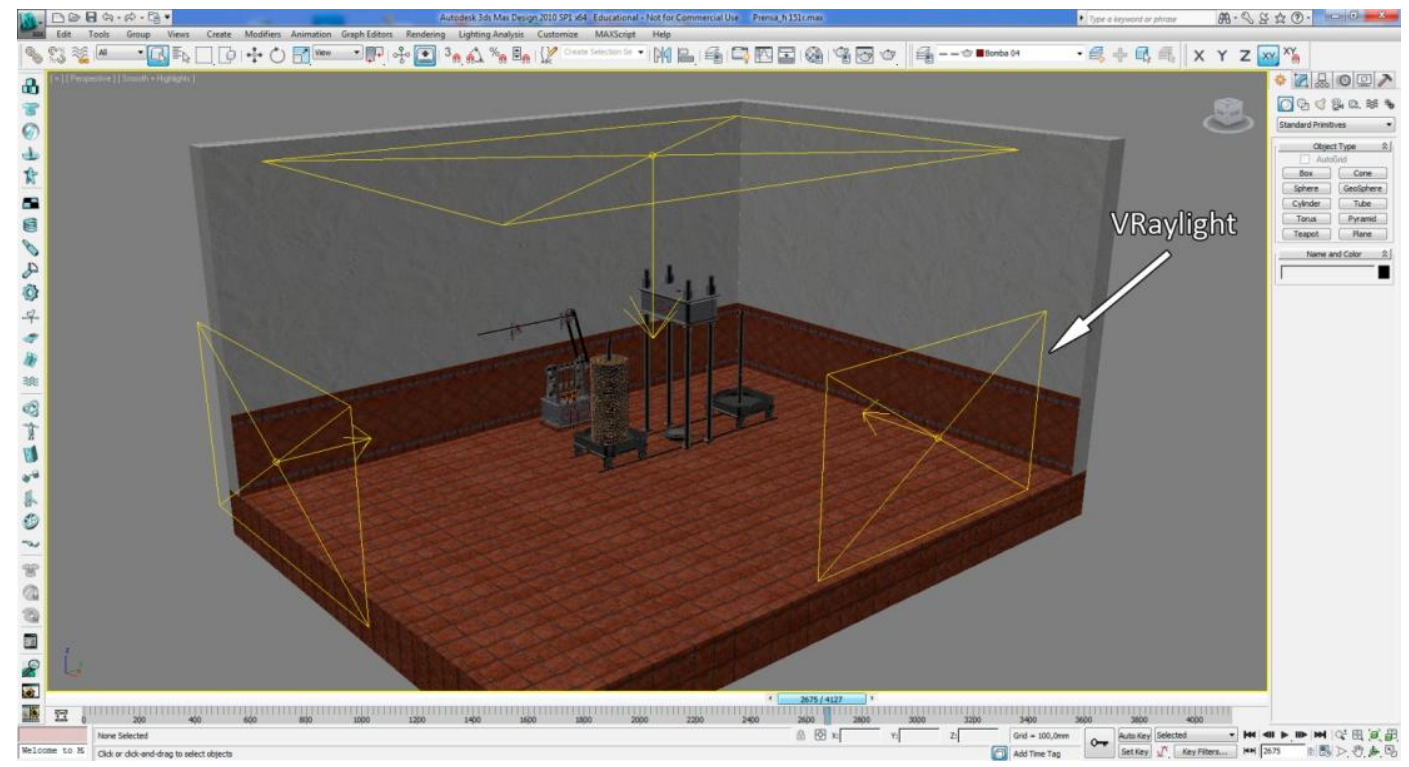

Figure 4. Scene lighting with V-ray light.

shutter speed or sensitivity to light (ISO).

\section{Computer animation}

Computer animation forms part of a new methodology for the recovery, dissemination and updating of historical industrial heritage (Suárez-Quirós et al., 2009). In general, traditional animation is defined as the technique which creates the illusion of movement by presenting the eye with a sequence of images at an appropriate speed. In the case of computer animation, the technique is the same, but the difference is in the way the image is obtained, as each frame is generated from a virtual environment.

There are many programs for modeling, image synthesis and computer animation, but the most wellknown are Autodesk 3ds Max Design, Autodesk Maya and Blender. Both the movement of objects and those of the cameras are created using the initial and final coordinates, and can be perfected by adding known intermediate points. The animation software generates an interpolation which presents different approximations between these points in space, which in turn gives the complete movement. However, in computer animation it is not a case of change of position, but its relationship with the timeline on which the action occurs. The most usual configuration parameters for modification according to time are those related to lighting and cameras.

However, the animation is somewhat more complex than establishing a relationship between the coordinates of an object with respect to the time line, as many variables have to be introduced in order to simulate the physical laws governing the real world which affect all the elements of a scene. There are therefore a large number of modules, extensions and techniques to imitate these effects; in particular, physical effects such as gravity or particle generation may be used, among many possibilities.

\section{Rendering}

Rendering is the computational process of a $3 \mathrm{D}$ virtual scene which provides a raster image, establishing a perspective and resolution parameters with given variables. There are many rendering engines such as Mental Ray, V-Ray, Brazil, Maxwell Render, and Final render, Fprime, Scanline, Mantra, Arnold or Nvidia Gelato, among

others.

In our case, we have used the rendering engine provided by V-Ray (www.chaosgroup.com), integrated into Autodesk 3Ds Max as a plug-in, although, there are others such as; Mental ray. The version used is 1.5 SP5, an application which is especially recommended for obtaining infographics of architectural interiors and exteriors, as well as for giving high quality results in a short time. As well as its own image generation engine, V-Ray has its own system of materials, lighting and cameras, allowing the process of rendering and infographics to be carried out in a shorter time than with other engines. This is one of the key advantages of $\mathrm{V}$ Ray, along with the realism of the scenes (Figure 5).

The generation of infographics using rendering can be carried out in two ways: by creating directly a video sequence, or by using the sequence of frames to make the video. The first option is simpler and generates 


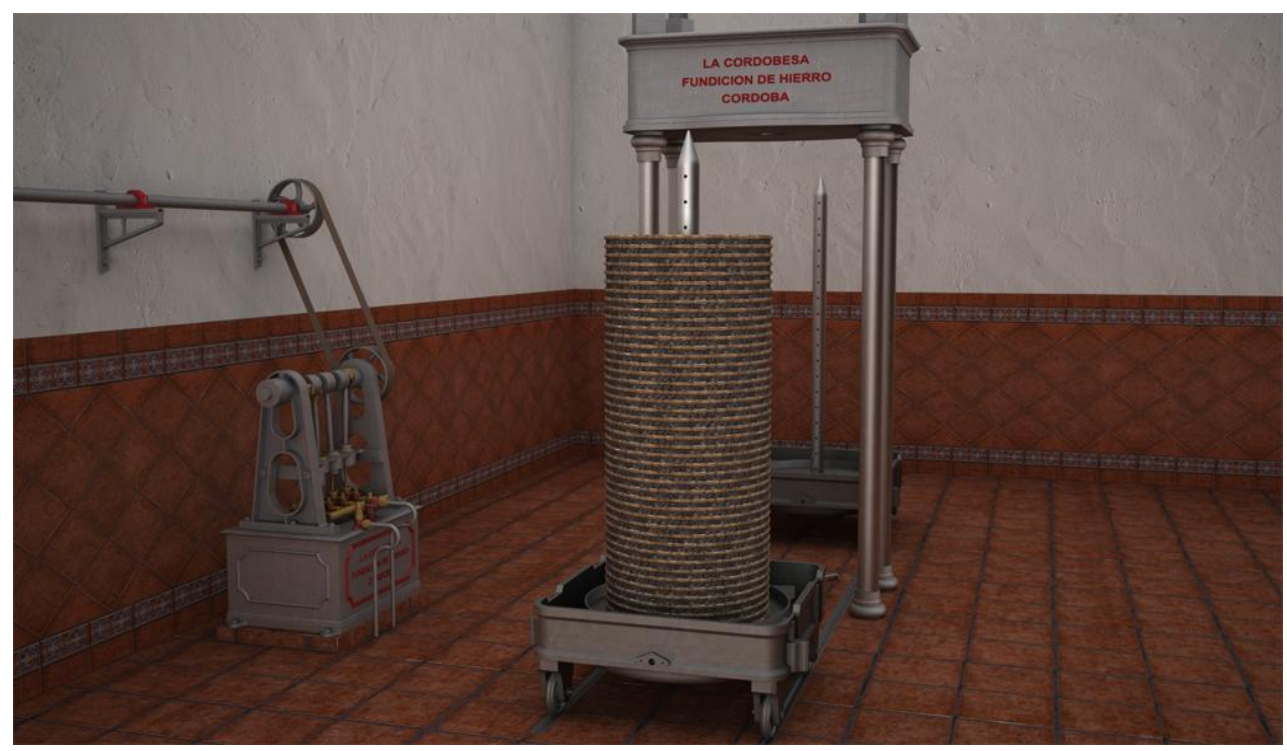

Figure 5. Realistic frame obtained in the rendering process.

greater amount of information. The second option is more complex, but offers greater possibilities for enhancement in the post-production stage; this option is more usually chosen.

\section{Digital post-production}

In general terms, post-production is the editing of the digital material in order to provide effects and transitions for the final product. The sources edited are video and audio. Here there is also a range of commercial software available, and one of the most common software packages used professionally for real-time video editing is Adobe Premiere (Figure 6).

\section{Interaction techniques: Augmented reality and virtual reality}

There are currently two new techniques for interaction with industrial heritage which are increasingly used: augmented reality and virtual reality. Augmented Reality (AR) is considered as the perception of the real environment, directly or indirectly, including virtual elements as a complement or with the aim of increasing perception. It uses standard methodologies and techniques applied in many fields, as is the case of historical industrial heritage. Some projects have the objective of preserving archaeological remains, which is the case of the PRISMA project (www.realidadaumentada.es), where 3D techniques are applied to touristic and cultural applications. Augmented reality presents various interaction techniques for the user with the system. In general, these can be summarized as follows:

\section{Tangible interfaces based on the use of markers}

These are based on the recognition of a marker by an image capture device, such as a webcam or the digital camera of a mobile device. When the marker is located and identified, a 3D model or other multimedia file from the real or virtual environment is superposed on the real image, and the movements made by the marker are extrapolated. The marker is usually in one of two forms: printed or projected on any part of an object.

\section{Multimodal interactions}

This technique consists of using natural input methods such as the voice, pencil and body movements which are recognized, and form the interaction between reality and the virtual elements. For this function, it is necessary to use specific peripherals such as AR Mask, or other nonspecific devices such as a digital camera, microphones or accelerometers.

\section{Other interaction techniques}

Many applications are currently being developed which use augmented reality as the basis of their operation. One of the most successful is the integration of GPS technology with mobile phone devices, such as smartphones. With these, it is possible to introduce 


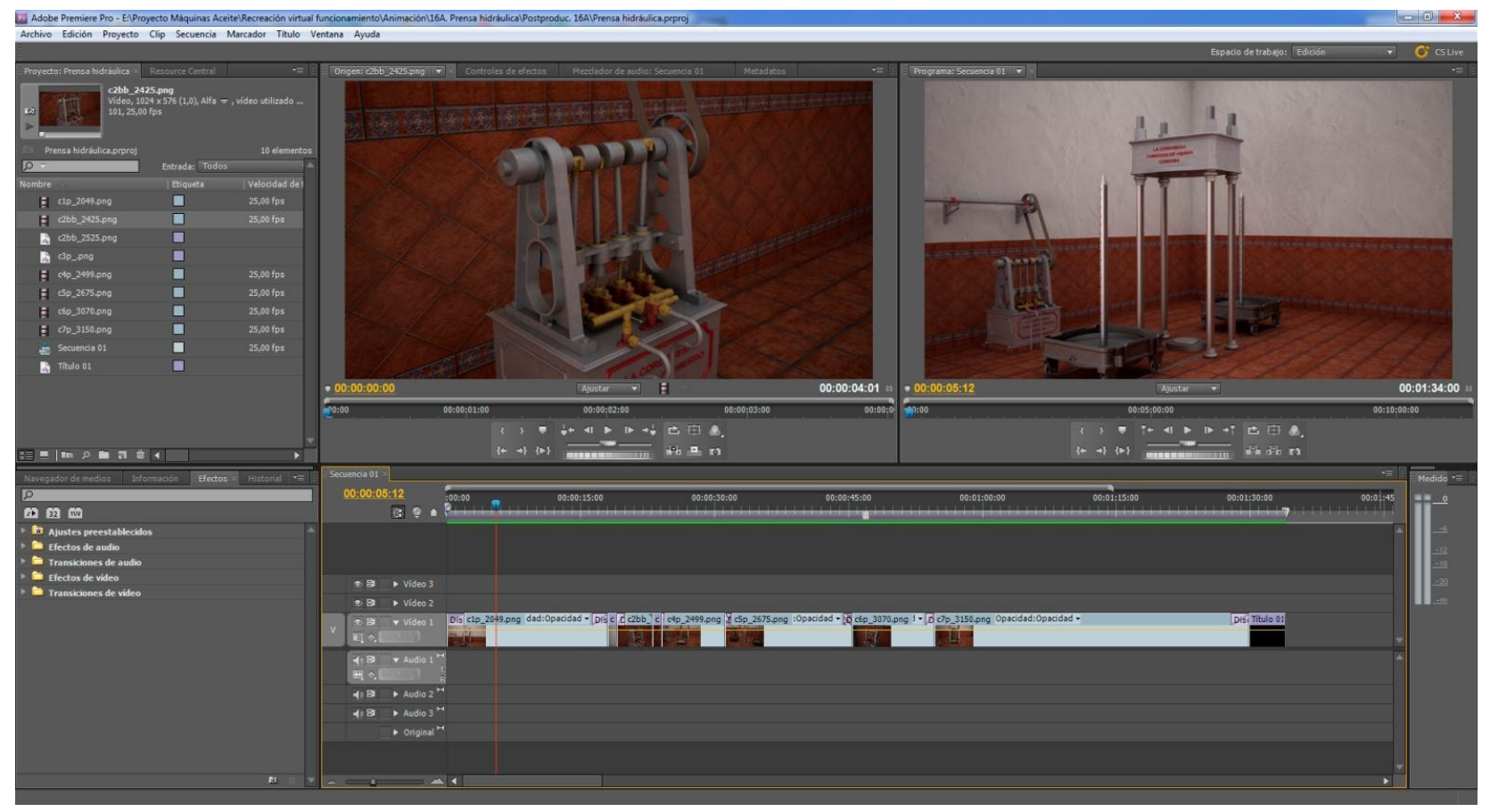

Figure 6. Screenshot of the digital post-production process in Adobe Premiere.

elements of a virtual environment into the images captured by the digital camera of the real environment, according to the GPS coordinates.

Another form of interaction is using an AR Pad, which is a system made up of a joystick, visual sensor and a marker, in which the virtual model is generated.

There are many publications which give a wide panorama of the application of augmented reality to virtual heritage (Noh et al., 2009) and even of the combination of photogrammetric techniques with augmented reality in the field of cultural heritage (Portales et al., 2009). It is useful here to give a brief summary of some of their characteristics.

On the other hand, interaction with Virtual Reality (VR) is known as immersion, and a person can participate using different interaction methods, either natural or not natural. At the other extreme is non-immersive reality, which offers no possibility for interaction between the virtual environment and the user. However, the immersion which is most commonly used today uses interaction based on body movements, transmitted to different hardware such as a mouse, and which uses mainly sight and hearing. This is known as partial immersion.

The idea here is to achieve a virtual environment in which the user can interact freely with the model under study, in line with the requirements of current hardware. There exist many tools for the development of virtual environments, according to the objectives. However, one organization is notable for establishing standards and tools for virtual reality on a web platform: Web3D
Consortium (www.web3d.org). Its main activity is the creation and improvement of a 3D graphic file format which can be freely distributed on the web. At the outset of the consortium (1994), the standard which was selected and distributed was Virtual Reality Modeling Language (VRML), version 1. In 1997 the standard VRML97 was introduced, which was on the market until 2002. In parallel, its successor was developed, called Extensible 3D (X3D).

VRML is recognised by the International Organization for Standardization (ISO) as a standard for the creation, distribution and representation of 3D elements on internet. The first version was developed to represent static 3D environments to be viewed by a single user. However, expectations were not fulfilled, as it did not allow for animation or manipulation of objects. These deficits were corrected in 1997 with the creation of VRML97 (ISO/IEC 14772-1:1997).

In terms of language, it has a hierarchical structure composed of nodes, events and fields, both for static and dynamic environments.

Continuing with the standards developed by Web3D Consortium, the first versions of the X3D standard were developed from 1997 to 2002, when the definitive version was launched (ISO/IEC FDIS 19775:200x). It is a standard which is integrated into Extensible Markup Language (XML).

X $3 \mathrm{D}$ corrects many deficits which were present in its predecessor. Some of the most important are:

1. It has increased graphic capacity (API). 
2. It is a unified and revised programming model.

3. It has different coding methods for files which describe abstract

models, such as XML.

4. It has a modular architecture allowing different levels of adoption (children).

5. It allows for specific uses according to needs, which is ideal for companies which develop their own modules.

In addition, Web3D Consortium offers the tool X3D-Edit for graphics based on X3D which represents the creation, verification, visualization and publication of the environments created. It is an application which is written in Java and AML which uses an open development environment called Netbeans (http://netbeans.org/index.html), with an open source licence. Its interface combines a viewer of the virtual environment and the code, as well as the program's own tools. Once the virtual reality scenes have been obtained and configured according to the browser, lighting, animation and sensors, it is necessary to have a suitable browser to be able to interact with them. There is a wide range of available browsers, some of which are members of Web3D Consortium, among which the most important are Cosmo Player, FreeWRL, OpenVRML, and Cortona3D Viewer y Octaga Player.

\section{DISSEMINATION}

This last stage is key to publishing the results obtained in previous stages of the research. Many of the results obtained about historical industrial heritage are often presented in many different forms.

Firstly, the contents can be incorporated into a physical museum. The design and presentation of these contents is very important to be able to reach out to a large audience which is not skilled in the area. However, the urrent trend is towards the creation of virtual museums, and there are very interesting publications which give a general view and other aspects which must be borne in mind in the design of a virtual museum (Sylaiou et al., 2009), as well as, the need to explore the relationship between the presence in and enjoyment of a virtual museum (Sylaiou et al., 2010).

A second way of publishing content is through the developments of a Content Management System (CMS) (Rojas-Sola et al., 2011a), which is one of the most dynamic and modern ways of presenting information.

\section{Advantages and disadvantages of the virtual reconstructions: Deficiencies and problems}

Here, outlines the main advantages and disadvantages or problems of virtual reconstructions, without going into the detail of each of the specific advantages or problems of the techniques shown as aforementioned.

Graphic techniques applied to virtual reconstruction have been used for several decades. However, these technique have evolved with the introduction of information which comes directly from the real location; the greater the amount of real information, the less virtual the model. Augmented reality is the most 'real' within a virtual environment (Milgram y Kishino, 1994).

Irrespective of how virtual a reconstruction is, graphic techniques have two main stages: one relating to recording information, and another relating to the graphic representation of the data.

Data capture is a key point, and there are many methodologies for graphic processing. For example, to record geometric data, techniques range from empirical data collection, such as direct measurement using a tape measure, to the use of a 3D laser scanner for objects (Bruno et al., 2010) or for large-scale areas (Ergun et al., 2010), and therefore the use of one or another technique will determine the accuracy of the virtual reconstruction. However, the accuracy of the record will depend on the relevance and physical features of the reconstruction.

The virtual reconstruction is carried out based on existing remains and historical information, and will depend on the form of interaction and the presentation format made available to the end user, either for a general or specialized audience. In addition, the amount of virtual content and the representation format are important when deciding which interaction technology with the user should be chosen. One example can be found in the immersive reality used for the virtual reconstruction of museums (Carrozzino and Bergamasco, 2010) or the introduction of holograms using laser techniques (Bjelkhagen, 2011), among others.

Therefore, an important advantage of the first step in virtual reconstruction (recording information) is the generation of $2 \mathrm{D}$ and 3D information, which is saved in a permanently open database with minimal maintenance. Thus, the virtual reconstruction can be seen as a constant source of information, irrespective of the state of conservation of the cultural element under study. In addition, more traditional recording techniques cannot be reproduced, exchanged and do not last as long as virtual records.

However, the main disadvantage is the limitation of technology, as this affects the capture of all the information relating to the cultural element and its record.

The second stage of virtual reconstruction (graphic representation) is highly dependent on the media used for its representation and on the final user. A clear example is the evolution of museums. These were originally physical spaces with real heritage examples, but in time some have become completely virtual, with real examples and virtual reconstructions.

It is clear that virtual reconstruction is appropriate provided that it fulfils its function, and at the same time 
uses the technical resources available at the time of its creation. Therefore, a big problem for virtual reconstruction is the speed at which technology becomes obsolete, which forces virtual reconstructions to be updated regularly in order to adapt to new means of interaction with the end user. This involves increased cost.

However, the great advantage of graphic representation is that it is a database which can be consulted, and so any updating does not mean a loss of historical reliability. An example can be seen when comparing real-life and virtual reconstruction. The former involves a large investment and is carried out with the information known at a given time. In contrast, virtual reconstruction conserves any original remains that exist, proposes solutions for elements which no longer exist and gives the possibility to modify these solutions simply with new information. Therefore, virtual reconstruction acquires a level of realism, as it can provide more possibilities for types of visits from given user profiles.

\section{Conclusion}

This overview has shown the complexity of the treatment of information relating to historical industrial heritage, in order to promote its value and dissemination, along with the use of new technologies; these are principal stages in the heritage value chain.

The intrinsic complexity of this type of heritage, owing to the incorporation of operation, means that its study, analysis and recovery are especially interesting, as this implies a great depth of knowledge and updating of the newest techniques, for instance data capture and engineering graphics techniques (3D modeling, virtual recreation, augmented reality, virtual reality or digital post-production).

In addition to the need to be up to date with this technical knowledge, it is necessary to optimize the dissemination of the results, either through the creation of a virtual museum or a CMS, which brings the public closer to the heritage under study and its technology, and allows us to know the technological evolution of areas where the heritage elements were located.

\section{ACKNOWLEDGEMENTS}

This research was funded by the Research Project entitled "Infographic techniques and industrial engineering as a tool of history of technology for Museums and Interpretation Centres of olive oil" (HAR2009-06459) granted by the Ministry of Science and Innovation of the Spanish Government.

\section{REFERENCES}

Addison AC (2000). Emerging trends in virtual heritage. IEEE
Multimedia 7: 22-25.

Alkan M, Bulut G (2010). GIS and remote-sensing-based urbaninformation system design and development: A case study for Kozlu, Zonguldak, Sci. Res. Essays, 5: 2889-2899.

Alyilmaz C, Yakar M, Yilmaz HM (2010). Drawing of petroglyphs in Mongolia by close range photogrammetry, Sci. Res. Essays, 5: 12161222.

Arnold D (2001). Virtual heritage: Challenges and opportunities. In Digital content creation, Springer-Verlag, USA, pp. 281-293.

Aydin EO, Ergun B, Sahin C (2010). Documentation of an Ottoman replica tile via photogrammetric modeling, Sci. Res. Essays, 5: 19781985.

Bakker G, Meulenberg F, De Rode J (2003). Truth and Credibility as a Double Ambition: Reconstruction of the Built Past, Experiences and Dilemas. J. Vis. Comput. Animat., 14: 159-167.

Bjelkhagen $\mathrm{HI}$ (2011). Colour holography: the ultimate 3D imaging technique. Imaging Sci. J. 59: 83-89.

Bruno F, Bruno S, De Sensi G, Luchi ML, Mancuso S, Muzzupappa M (2010). From 3D reconstruction to virtual reality: A complete methodology for digital archaeological exhibition. J. Cult. Herit., 11: 42-49.

Buchanan RA (1972). Industrial Archaeology in Britain, Penguin Books, England.

Carrozzino M, Bergamasco M (2010). Beyond virtual museums: Experiencing immersive virtual reality in real museums. J. Cult. Herit., 11: 452-458.

Ergincan F, Çabuk A, Avdan U, Tün M (2010). Advanced technologies for archaeological documentation: Patara case, Sci. Res. Essays, 5: 2615-2629.

Ergun B, Sahin C, Baz I, Ustuntas T (2010). A case study on the historical peninsula of Istanbul based on three-dimensional modeling by using photogrammetry and terrestrial laser scanning. Environ. Monit. Assess., 165: 595-601.

Fuentes JM, Gallego E, Garcia Al, Ayuga F (2010). New uses for old traditional farm buildings: The case of the underground wine cellars in Spain. Land Use Policy, 27: 738-748.

Fuentes JM, Garcia Al, Ayuga E, Ayuga F (2010). The development of the flour-milling industry in Spain: analysis of its historical evolution and architectural legacy. J. Hist. Geogr., 37: 232-241.

Garcia-Fernández I (2003). Synthesis and intercative visualization of embossed textures. PhD dissertation. University of Gerona, Spain.

Goktepe A (2010). A study on the calibration of stereo photogrammetric systems used in motion analysis, Sci. Res. Essays, 5: 2491-2496.

Hudson K (1971). A guide to the industrial archaeology of Europe, Adams \& Dart, England.

Laeuferts M, Mavunganidze J (2009). Ruins of the past: industrial heritage in Johannesburg. In: Structural studies, repairs and maintenance of heritage architecture XI Book Series: WIT Transactions on the Built Environment, Czech Republic, 109: 533542.

Martin Lerones P, Llamas Fernandez J, Melero Gil A, Gomez-GarciaBermejo J, Zalama Casanova E (2010). A practical approach to making accurate $3 \mathrm{D}$ layouts of interesting cultural heritage sites through digital models. J. Cult. Herit., 11: 1-9.

McAdams MA, Kocaman S, Kara F (2010). The use of remote sensing in the protection and management of archaeological sites: a case study of the Anastasian wall. Sci. Res. Essays, 5:55-62.

Med T (2010) Industrial heritage towards sustainability. In: Central Europe towards sustainable building - from theory to practice, Czech Republic, pp. 141-144.

Milgram P, Kishino F (1994). A taxonomy of mixed reality visualdisplays. In: IEICE transactions on information and systems, E77D: 1321-1329.

Montoro L, Pujol T, Pelegri M, Gonzalez JR, Velayos J (2010). Classical renewable hydro-energy devices: The case of an ancient Spanish watermill. In: Environmental hydraulics: theoretical, experimental and computational solutions, Valencia (Spain), pp. 289-292.

Noh Z, Sunar MS, Pan ZG (2009). A Review on Augmented Reality for Virtual Heritage System. Lect. Notes Comput. Sc., 5670: 50-61.

Pennestri E, Pezzuti E, Valentini PP, Vita L (2006). Computer-aided virtual reconstruction of Italian ancient clocks. Comput. Animat. Virtual Worlds, 17: $565-572$. 
Perez-Martin E, Herrero-Tejedor TR, Gomez-Elvira Gonzalez MA, Rojas-Sola JI, Conejo-Martin MA (2011). Graphic study and geovisualization of the old windmills of La Mancha (Spain), Appl. Geogr., 31: 941-949.

Popovici DM, Querrec R, Bogdan CM, Popovici N (2010). A Behavioral Perspective of Virtual Heritage Reconstruction. Int. J. Comput. Commun. Control, 5: 884-891.

Portales C, Lerma JL, Perez C (2009). Photogrammetry and augmented reality for cultural heritage applications. Photogramm. Rec., 24: 316331.

Refsland ST, Ojika T, Addison AC, Stone RJ (2000). Virtual heritage: Breathing new life into our ancient past. IEEE Multimedia, 7: 20-21.

Rojas-Sola JI (2005). Ancient technology and Computer-Aided Design: olive oil production in southern Spain. Interdiscip. Sci. Rev., 30: 5967.

Rojas-Sola JI, Amezcua-Ogayar JM (2005a). Technical and graphical comparison of windmills in Spain. Interciencia, 30: 339-345.

Rojas-Sola JI, Amezcua-Ogayar JM (2005b). Southern Spanish windmills: Technological aspects. Renew. Energy, 30: 1943-1953.

Rojas-Sola JI, Domene-Garcia J (2005). Engineering and computeraided design: Study of watermills in southeastern Spain. Interciencia, 30: 745-751.

Rojas-Sola JI (2006). Cultural heritage and information technologies: Improvement proposals for science and technology museums and interactive centers of Venezuela. Interciencia, 31: 664-670.

Rojas-Sola JI, Gomez-Elvira Gonzalez MA, Perez-Martin E (2006). Computer-aided design and engineering: a study of windmills in $\mathrm{La}$ Mancha (Spain). Renew. Energy, 31: 1471-1482.

Rojas-Sola JI, Lopez-Garcia R (2007a). Engineering graphics and watermills: ancient technology in Spain. Renew. Energy, 32: 20192033.

Rojas-Sola, Jl., López-García, R. (2007b). Computer-aided design in the recovery and analysis of industrial heritage: Application to a watermill. Int. J. Eng. Educ., 23: 192-198.

Rojas-Sola JI, Suarez-Quiros J, Rubio-Garcia R (2007). The tradition of fulling mills: A study from engineering, Interciencia, 32: 675-678.

Rojas-Sola JI, Contreras-Anguita FJ (2010). Computer animation applied to the recovery of preindustrial heritage: A new approach. In: Computer Animation, Nova Science Publishers, USA, pp. 1-58.
Rojas-Sola JI, Castro-Garcia M, Carranza-Canadas, MP (2011a). Content Management System incorporated in a virtual museum hosting, J. Cult. Herit., 12: 74-81.

Rojas-Sola JI, Castro-Garcia, M, Carranza-Canadas, MP (2011b). Improvement proposal in the treatment dissemination of the results of computer graphics in the study and analysis of cultural heritage. In: Computer Graphics, Nova Science Publishers, USA, pp. 83-95.

Stone RJ, Ojika T (2000). Virtual Heritage: What Next?. IEEE Multimedia, 7: 73-74.

Suarez-Quiros J, Rojas-Sola JI, Rubio-Garcia R, Martin-Gonzalez S, Moran-Fernandez S (2009). Teaching applications of the new computer-aided modelling technologies in the recovery and diffusion of the industrial heritage, Comput. Appl. Eng. Educ., 17: 455-466.

Sylaiou S, Liarokapis F, Kotsakis K, Patias P (2009). Virtual museums, a survey and some issues for consideration. J. Cult. Herit., 10: 520528.

Sylaiou S, Mania K, Karoulis A, White M (2010). Exploring the Relationship between Presence and Enjoyment in a Virtual Museum. Int. J. Hum.-Comput. Stud., 68: 243-253.

Tuck D, Kuksa T (2009). Virtual Heritage Tours: Developing Interactive Narrative-Based Environments for Historical sites. Lect. Notes Comput. Sc., 5915: 336-339.

Valle MJM (2007). Geometric Heritage Documentación: conceptual and methodological proposal. PhD dissertation, University of La Rioja, Logroño, Spain.

Valle Melón JM (2009). From historical heritage to digital heritage: Strategies for information assurance and quality. In: Innovations in information technologies applied to heritage information, Association of cultural managers of Extremadura, Spain, pp. 155-166.

Yakar M, Alyilmaz C, Telci A, Baygul E, Çolak S, Aydin M, Alyilmaz S, Yilmaz HM (2009). 3D laser scanning and photogrammmetric measurement of Akhan caravansaray. Sci. Res. Essays, 4: 15651568. 